Interdependence of Point Defects and Reaction Kinetics:

$\mathrm{CO}$ and $\mathrm{CH}_{4}$ Oxidation on Ceria and Zirconia

Maximilian Schaube, Rotraut Merkle*, Joachim Maier

Max Planck Institute for Solid State Research, Stuttgart, Germany

\title{
Supplementary
}

\section{Details of sample preparation}

Doped ceria and zirconia samples were synthesized by a Pechini type approach ${ }^{1-3}$. $\mathrm{Gd}, \mathrm{Pr}$, and $\mathrm{Nb}$ doped ceria samples were synthesized by using $\mathrm{Me}\left(\mathrm{NO}_{3}\right)_{3} \times \mathrm{H}_{2} \mathrm{O}(\mathrm{Me}$ : $\mathrm{Ce}, \mathrm{Gd}$ or Pr) (REacton, Alfa Aesar, $99.99 \%$ ) and $\mathrm{NH}_{4} \mathrm{NbC}_{2} \mathrm{O}_{4} \times \mathrm{H}_{2} \mathrm{O}$ (Aldrich) in the desired molar ratios. For Pr-doped zirconia, $\mathrm{ZrO}\left(\mathrm{NO}_{3}\right)_{2} \cdot x \mathrm{H}_{2} \mathrm{O}$ (Aldrich, $99.99 \%$ ) was used as reagent. The exact water content was determined by thermogravimetry. Citric acid (CA) (Roth, >99.5\%) and ethylene glycol (EG) (Emsure, Merck) were added to a solution of $60 \mathrm{~mL}$ distilled water and $87 \mathrm{mmol}$ metal salts with a few droplets of conc. $\mathrm{HNO}_{3}$ (Roth, p.a.) where the molar ratio of EG/CA is two and for EG/Me one. The mixture was stirred at $175^{\circ} \mathrm{C}$ until a yellow resin was formed. After subsequent pyrolysis at $T \approx 250^{\circ} \mathrm{C}$ in the glass beaker, the obtained powder was homogenized by dry milling in a zirconia mill for $45 \mathrm{~min}$ followed by a calcination step at $800{ }^{\circ} \mathrm{C}$ with $300{ }^{\circ} \mathrm{Ch}^{-1}$ in air for $8 \mathrm{~h}$. For Y-stabilized zirconia (YSZ) commercial available Y-doped zirconia was used (TOSOH TZ8, composition $\left.\mathrm{Zr}_{0.96} \mathrm{Y}_{0.14} \mathrm{O}_{1.93}\right)$.

For $\mathrm{CO}$ and $\mathrm{CH}_{4}$ oxidation and pulsed oxygen isotope exchange (PIE) experiments the calcined powders were sieved to $60-100 \mu \mathrm{m}$ to break agglomerates. For in situ $\mathrm{CO}$ and $\mathrm{CH}_{4}$ oxidation measurements by thermogravimetric analysis approximately $1 \mathrm{~g}$ of the calcined powder was compacted into a dense pellet by spark plasma sintering (FCT-DP D 5/2, FCT Systeme, Germany). The sample was compacted at $1000^{\circ} \mathrm{C}$ for 3 minutes in a graphite mold $(\varnothing 10 \mathrm{~mm})$ with a heating/cooling rate of $200{ }^{\circ} \mathrm{C} \mathrm{min}{ }^{-1}$ at $6 \mathrm{kN}$ pressure in 25 mbar Ar atmosphere. The obtained pellets were annealed at $1400{ }^{\circ} \mathrm{C}$ for $8 \mathrm{~h}$ in air with $100{ }^{\circ} \mathrm{C} \mathrm{h}^{-1}$. The sintered pellets where crushed and sieved to obtain a particle size $<60 \mu \mathrm{m}$.

For in situ $\mathrm{CO}$ oxidation investigated by electrochemical impedance spectroscopy (EIS) $0.5 \mathrm{~g}$ of the calcined powder was compacted by isostatic pressing at $250 \mathrm{kN}$ in a silicon rubber mold (ø $10 \mathrm{~mm}$ ). The green body was sintered at $850{ }^{\circ} \mathrm{C}$ for $8 \mathrm{~h}$ with $100{ }^{\circ} \mathrm{C} \mathrm{h}^{-1}$ to achieve a porous sample with a mean density of $72 \%$.

\section{Details of Sample Characterization and Kinetic Measurements}

X-Ray diffraction: Phase purity and lattice parameters were examined by X-ray diffraction (Panalytical Empyrean) with $\mathrm{Cu} \mathrm{K} \alpha$ radiation $(40 \mathrm{~kW}, 40 \mathrm{~mA})$ in BraggBrentano reflection geometry.

Cation stoichiometry: The cation stoichiometry was checked by inductively coupled plasma optical emission spectroscopy (Spectro Ciros CCD, Spectro Analytical Instruments). Scanning electron microscopy: The morphology of the powders was investigated by a Merlin Gemini II scanning electron microscopy (Carl Zeiss). 
BET: Surface area measurements were performed by using nitrogen as adsorption gas (AUTOSORB-1, Quantachrome Instruments). Prior to measurements, the samples were treated at $120^{\circ} \mathrm{C}$ in vacuum to desorb adsorbates.

Thermogravimetric analysis, TG: TG (STA 449 C, Netzsch) was performed with crushed ceramic particles $(<60 \mu \mathrm{m}, \approx 0.7 \mathrm{~g})$ in $10-830 \mathrm{mbar}_{2}$ (data in fig. $2 \mathrm{a}$ ), and a mixture of 10 mbar $\mathrm{O}_{2}$ with 10 mbar $\mathrm{CO}$ or $2.5 \mathrm{mbar}^{\mathrm{CH}_{4}}$. The total gas flow was $30 \mathrm{~mL} \mathrm{~min}-1$, and heating rates between $2{ }^{\circ} \mathrm{C} \mathrm{min}-1$ (high $T$ ) and $0.3{ }^{\circ} \mathrm{C} \mathrm{min}-1$ (low T) to ensure steady state, which was checked also by comparing heating and cooling curves. Buoyancy correction was done using a measurement of an empty $\mathrm{Al}_{2} \mathrm{O}_{3}$ crucible.

UV-Vis spectroscopy: Spectroscopy was performed on the calcined powders with a Cary Series UV-Vis-NIR spectrometer (Agilent Technologies) in diffuse reflectance mode with a reduced slit height and a scan rate of $600 \mathrm{~nm} \mathrm{~min}{ }^{-1}$ with a resolution of $1 \mathrm{~nm}$ from $800-200 \mathrm{~nm}$ at room temperature. The samples were diluted with $75 \%$ zirconia (TZ-0, TOSOH). Reflectance spectra were converted to the Kubelka-Munk function.

Raman spectroscopy: Raman spectroscopy was performed with a Jobin Yvon Typ V 010 LabRAM (HORIBA) single grating spectrometer with a resolution of approx. $1 \mathrm{~cm}^{-1}$ at room temperature. The linear polarized He/Ne gas laser with $\lambda=633 \mathrm{~nm}$ with $<1 \mathrm{~mW}$ power was focused on the particle surface by a microscope (spot size approx. $10 \mu \mathrm{m})$.

Electrochemical impedance spectroscopy, EIS: EIS measurements were performed by a Novocontrol Alpha-A high performance frequency analyzer in 100 mbar $\mathrm{O}_{2}$ and a mixture of $100 \mathrm{mbar}_{2}$ with $100 \mathrm{mbar} \mathrm{CO}$ with a total flow rate of $50 \mathrm{~mL} \mathrm{~min}^{-1}$. Au was used as electrode material.

Plug flow reactor: $\mathrm{PIE} 4-9, \mathrm{CO}$, and $\mathrm{CH}_{4}$ oxidation reaction experiments were conducted in a vertical $\mathrm{Al}_{2} \mathrm{O}_{3}$ micro plug flow reactor (inner diameter $2 \mathrm{~mm}$, length $300 \mathrm{~mm}$, Friatec AG) loaded with $15-25 \mathrm{mg}$ of the sample fixed by $15 \mathrm{mg}$ of a quartz wool plug. The $\mathrm{SiO}_{2}$ wool was pre-treated in concentrated $\mathrm{HNO}_{3}$ overnight and annealed at $800^{\circ} \mathrm{C}$ for $4 \mathrm{~h}$ in air with a heating/cooling rate of $200 \mathrm{C} \mathrm{h}^{-1}$. The bed height was between $4-8 \mathrm{~mm}$ and the pressure drop across the packed bed was always below $20 \%$. In the investigated temperature regime the quartz wool plug (or the homogeneous gas phase reaction) did not show any conversion. The carrier gas enters the reactor at the top with a flow rate of 5 or $25 \mathrm{~mL} \mathrm{~min}^{-1}$ depending on the gas composition (Aera TC FC-R7800CD, Alicat MC Mass Flow Controller). Prior to each measurement, the samples were pre-treated in the experimental setup at an appropriate gas composition and flow at $750{ }^{\circ} \mathrm{C}$ for $30 \mathrm{~min}$ with a heating/cooling rate of $5^{\circ} \mathrm{C} \mathrm{min}^{-1}$. The exiting gas was analyzed by online mass spectrometry (Balzers Prisma QME200, Pfeiffer Vacuum).

Pulsed oxygen isotope exchange, PIE: Experimental details for PIE measurements can be found elsewhere ${ }^{10}$. However, in the present study isotope exchange was performed in $1 \% \mathrm{O}_{2}$ with a flow rate of $7 \mathrm{~mL} \mathrm{~min}^{-1}$, and using calcined powders. 
$\mathrm{CO} / \mathrm{CH}_{4}$ oxidation: For $\mathrm{CO}$ oxidation experiments traces of $\mathrm{Ni}$ tetracarbonyl (formed in the metal tubing) were removed prior to the reactor by a separate packed bed reactor filled with $\mathrm{SiO}_{2}$ wool at $260{ }^{\circ} \mathrm{C}$. Prior to $\mathrm{CO} / \mathrm{CH}_{4}$ oxidation measurements, the sample was pre-treated in the packed bed reactor in the appropriate carrier gas stream for $30 \mathrm{~min}$ at $750{ }^{\circ} \mathrm{C}$ with a heating/cooling rate of $5{ }^{\circ} \mathrm{C} \mathrm{min}^{-1}$. For $\mathrm{CO}$ oxidation, the carrier gas did not contain any nitrogen but argon to be able to recognize the $\mathrm{CO}$ signal $\left(\mathrm{N}_{2}\right.$ and $\mathrm{CO}$ have the same $\left.m / z\right)$. For $\mathrm{CH}_{4}$ oxidation, nitrogen was used. Conversions $X$ of $\mathrm{CO}$ and $\mathrm{CH}_{4}$ were measured as a function of $T, p\left(\mathrm{O}_{2}\right), p(\mathrm{CO})$, and $p\left(\mathrm{CH}_{4}\right)$ (gas compositions are listed in Table $\mathrm{S} 1$ )

Table S1: Gas compositions and volumetric flow rates used for $\mathrm{CO}$ and $\mathrm{CH} 4$ oxidation measurements. Bottled gas was used (Westfalen AG) with purities of: Ar (5.0), $\mathrm{N}_{2}(5.0), 20 \%$ $\mathrm{O}_{2}$ in Ar (both 5.0), $10 \% \mathrm{O}_{2}$ in $\mathrm{N}_{2}$ (both 5.0), $5 \% \mathrm{CH}_{4}$ in $\mathrm{N}_{2}\left(4.5 \mathrm{CH}_{4}, 5.0 \mathrm{~N}_{2}\right.$ ), and $5 \% \mathrm{CO}$ in Ar (4.7 CO, 5.0 Ar).

\begin{tabular}{|c|c|c|c|}
\hline Gas composition & 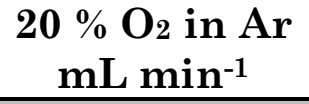 & $\begin{array}{c}5 \% \text { CO in Ar } \\
\text { mL min-1 }\end{array}$ & $\begin{array}{c}\text { Ar } \\
{\text { mL } \text { min }^{-1}}\end{array}$ \\
\hline $1 \% \mathrm{O}_{2} / 1 \% \mathrm{CO}$ & 0.50 & 2.00 & 7.50 \\
\hline $4 \% \mathrm{O}_{2} / 1 \% \mathrm{CO}$ & 2.00 & 2.00 & 6.00 \\
\hline $10 \% \mathrm{O}_{2} / 1 \% \mathrm{CO}$ & 5.00 & 2.00 & 3.00 \\
\hline $1 \% \mathrm{O}_{2} / 0.3 \% \mathrm{CO}$ & 1.25 & 0.50 & 23.25 \\
\hline $1 \% \mathrm{O}_{2} / 0.1 \% \mathrm{CO}$ & 1.25 & 2.50 & 21.25 \\
\hline Gas composition & 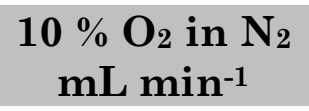 & $\begin{array}{c}5 \% \mathrm{CH}_{4} \text { in } \mathrm{N}_{2} \\
\mathrm{~mL} \mathrm{~min}^{-1}\end{array}$ & $\begin{array}{c}\mathrm{N}_{2} \\
\text { mL min }^{-1}\end{array}$ \\
\hline $1 \% \mathrm{O}_{2} / 0.25 \% \mathrm{CH}_{4}$ & 1.00 & 0.50 & 8.50 \\
\hline $3 \% \mathrm{O}_{2} / 0.25 \% \mathrm{CH}_{4}$ & 3.00 & 0.50 & 6.50 \\
\hline $9.5 \% \mathrm{O}_{2} / 0.25 \% \mathrm{CH}_{4}$ & 9.50 & 0.50 & 0 \\
\hline $5 \% \mathrm{O}_{2} / 0.1 \% \mathrm{CH}_{4}$ & 12.50 & 0.50 & 12.00 \\
\hline $5 \% \mathrm{O}_{2} / 0.3 \% \mathrm{CH}_{4}$ & 12.50 & 1.50 & 11.00 \\
\hline $5 \% \mathrm{O}_{2} / 1 \% \mathrm{CH}_{4}$ & 12.50 & 5.00 & 7.50 \\
\hline
\end{tabular}

The gas phase analysis was performed by mass spectrometry at the exit of the reactor with $m / z=28(\mathrm{CO}), 32\left(\mathrm{O}_{2}\right), 40(\mathrm{Ar}), 44\left(\mathrm{CO}_{2}\right)$ for $\mathrm{CO}$ oxidation and $m / z=15\left(\mathrm{CH}_{3}{ }^{+}\right), 18\left(\mathrm{H}_{2} \mathrm{O}\right), 28\left(\mathrm{~N}_{2}\right), 32\left(\mathrm{O}_{2}\right), 44\left(\mathrm{CO}_{2}\right)$ for $\mathrm{CH}_{4}$ oxidation. For methane oxidation the $\mathrm{CH}_{3}^{+}(\mathrm{m} / z=15)$ fragment was analyzed instead of $\mathrm{CH}_{4}^{+}(\mathrm{m} / z=16)$ since the latter signal is influenced by oxygen. The quantification of $\mathrm{CO}, \mathrm{CO}_{2}, \mathrm{CH}_{4}, \mathrm{O}_{2}$ and $\mathrm{H}_{2} \mathrm{O}$ was done by a linear two point calibration: at room temperature where no reaction takes place (the measured ion currents are equal to the inlet gas concentrations) and at higher temperatures, where total conversion of $\mathrm{CO}$ and $\mathrm{CH}_{4}$ occurs (concentrations of zero; the equilibrium $\mathrm{CO}+0.5 \mathrm{O}_{2} \rightleftharpoons \mathrm{CO}_{2}$ is completely on the right hand side because of the large thermodynamic driving force). In case of $\mathrm{CO}$ oxidation, the exiting gas stream was analyzed additionally by a CO sensor (TOX Sens, Kohlenmonoxid 300 ppm, Endresss+Hauser) to check for full conversion at high temperatures. Prior to calibration, the ion currents for $\mathrm{CO}$ and $\mathrm{O}_{2}$ were corrected in order to consider the fragmentation of $\mathrm{CO}_{2}$ and $\mathrm{H}_{2} \mathrm{O}$ in $\mathrm{CO}^{+}$and $\mathrm{O}^{+}$, respectively. The partial pressure and dopant concentration dependencies (figs. 4, 6a, S4, S5a) were measured/extracted under conditions with conversion below $30 \%$. 
Pulsed CO oxidation: The sample is kept in $1 \%{ }^{32} \mathrm{O}_{2}$ then a pulse containing $1 \%{ }^{36} \mathrm{O}_{2}+1 \% \mathrm{C} 16 \mathrm{O}$ was applied, and the reaction product pulse analyzed. The mass spectrometer peak areas were integrated over the pulse duration and normalized such that at $25^{\circ} \mathrm{C}$ (no conversion) the peaks at $\mathrm{m} / z=28\left(\mathrm{C}^{16} \mathrm{O}\right)$ and $36\left({ }^{36} \mathrm{O}_{2}\right.$, plus some ${ }^{36} \mathrm{Ar}$ isotope) reach unity, and at high $T$ (complete $\mathrm{CO}$ oxidation) $\mathrm{m} / z=44$ $\left(\mathrm{C}^{16} \mathrm{O}_{2}\right)$ and ${ }^{32} \mathrm{O}_{2}$ reach unity. At high $T, \mathrm{C}^{16} \mathrm{O}$ is largely (20GDC) or completely (20PDC) oxidized, and also some liberation of ${ }^{32} \mathrm{O}_{2}$ from oxygen isotope exchange can be recognized (the signal at $m / z=36$ does not drop to zero owing to a contribution from the ${ }^{36} \mathrm{Ar}$ isotope). The aim of the pulsed $\mathrm{CO}$ oxidation is mainly to support the Mars - van Krevelen mechanism (incorporation of unlabeled lattice oxygen $16 \mathrm{O}$ instead of labelled gas phase oxygen ${ }^{36} \mathrm{O}_{2}$ into the formed $\mathrm{CO}_{2}$ ), not to extract quantitative reaction rates.

Thermogravimetric in situ $\mathbf{C O}, \mathbf{C H}_{4}$ oxidation: For TG measurements under reaction conditions, the same gas mixtures were used as for the reactions in the packed bed reactor $\left(1 \% \mathrm{CO}+1 \% \mathrm{O}_{2}\right.$ (for fig. 9b,c also higher $\mathrm{O}_{2}$ or lower $\mathrm{CO}$ concentrations), $\left.0.25 \% \mathrm{CH}_{4}+1 \% \mathrm{O}_{2}\right)$. However, in order to avoid spurious contributions from adsorbed species (e.g. surface carbonates) instead of the calcined powders, sintered pellets crushed to a particle size of $<60 \mu \mathrm{m}$ were used. This also allows for better gas diffusion throughout the particle bed. With this size, the particles are still in the surface-limited regime ( $c f$. discussion in ref. ${ }^{10}$ ). Typical sample weights were in the range of $0.7 \mathrm{~g}$, to achieve sufficiently large weight changes for a quantitative thermogravimetric analysis. To allow for good contact with the gas phase, the sample particles were spread flat on the bottom of an $\mathrm{Al}_{2} \mathrm{O}_{3}$ crucible with about $1 \mathrm{~cm}$ diameter and a few $\mathrm{mm}$ height. However, it is clear that for such an arrangement a residence time cannot be defined.

The exhaust gas was monitored by mass spectroscopy. This showed that in the particle bed in the TG crucible the conversion was generally significantly lower than under the conditions of the plug flow reactor (a full quantitative comparison is not feasible because the surface area of the $<60 \mu \mathrm{m}$ particles is not exactly known, and the gas flow cannot be forced to pass completely through the particle bed). A semiquantitative analysis indicated that for $\mathrm{CO}$ oxidation $\left(1 \% \mathrm{CO}+1 \% \mathrm{O}_{2}\right)$ of $2 \mathrm{PDC}$ and $20 \mathrm{PDC}$ in the TG the conversion was max. $\approx 70 \%$ at $500{ }^{\circ} \mathrm{C}, \max . \approx 50 \%$ at $450{ }^{\circ} \mathrm{C}, \max . \approx 25 \%$ at $400{ }^{\circ} \mathrm{C}$, and $\max . \approx 10 \%$ at $350{ }^{\circ} \mathrm{C}$. This is significantly lower than in the plug flow reactor (fig. 3 a of the main paper). Thus, to good approximation one can assume that in an extended temperature range all particles in the sample bed experienced a gas composition with $p(\mathrm{CO}) / p\left(\mathrm{O}_{2}\right)$ ratio sufficiently close to the initial feed. Even at high $T$ and correspondingly high conversion for

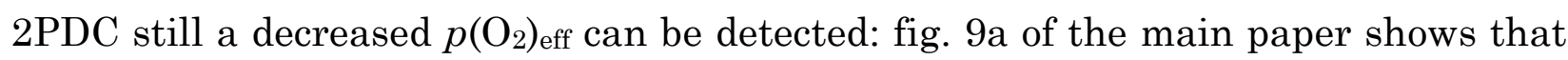
at $600{ }^{\circ} \mathrm{C}$ with $X>75 \%$ an apparent $p\left(\mathrm{O}_{2}\right)_{\text {eff }}=3 \cdot 10^{-4}$ bar is obtained (the real value should be a bit lower because the innermost particles of the bed experience a gas phase with higher conversion). The extraction of the $p\left(\mathrm{O}_{2}\right)$ and $p(\mathrm{CO})$ dependence of $p\left(\mathrm{O}_{2}\right)_{\text {eff }}$ at $450{ }^{\circ} \mathrm{C}$ and $500{ }^{\circ} \mathrm{C}$ yielded similar slopes $\left(2.2\right.$ and $-1.3\left(450{ }^{\circ} \mathrm{C}\right), 2$ and -1.4 $\left(500^{\circ} \mathrm{C}\right.$, fig. $9 \mathrm{~b}, \mathrm{c}$ of the main paper)) which confirms conditions of sufficiently low conversion. 
The effective oxygen partial pressure $p\left(\mathrm{O}_{2}\right)_{\text {eff }}$ (corresponding to the oxygen activity within the particles) was determined from comparison of oxygen deficiency $\delta=\left[\mathrm{V}_{0}^{\bullet \bullet}\right]$ in the reaction gas mixture with the measured dependence of the equilibrium oxygen stoichiometry (fig. 2 in the main paper) by extrapolating the plot of $\log (\delta) v s$. $\log p\left(\mathrm{O}_{2}\right)$ and reading the $p\left(\mathrm{O}_{2}\right)_{\text {eff }}$ value that corresponds to the oxygen stoichiometry recorded in the in situ $\mathrm{CO}$ oxidation experiment. This is illustrated for 2PDC, $500{ }^{\circ} \mathrm{C}$ in Fig. S1. The gray symbols are the oxygen deficiencies $\delta$ measured in inert gas $/ \mathrm{O}_{2}$ mixtures at different $T$ and $p\left(\mathrm{O}_{2}\right)$. $\delta$ is related to $p\left(\mathrm{O}_{2}\right)$ (and thus oxygen chemical potential) by the oxygen excorporation reaction

$\mathrm{O}_{\mathrm{O}}^{\mathrm{x}}+2 \mathrm{Pr}_{\mathrm{Ce}}^{\mathrm{x}} \rightleftharpoons 1 / 2 \mathrm{O}_{2}+\mathrm{V}_{\mathrm{O}}^{\bullet \bullet}+2 \mathrm{Pr}_{\mathrm{Ce}}^{\prime} \quad K(T)=\frac{\sqrt{p\left(\mathrm{O}_{2}\right)}\left[\mathrm{V}_{\mathrm{O}}^{\bullet}\right]\left[\operatorname{Pr}_{\mathrm{C}}^{\prime}\right]^{2}}{\left[\mathrm{O}_{\mathrm{O}}^{\mathrm{x}}\right]\left[\operatorname{Pr}_{\mathrm{Ce}}^{\mathrm{x}}\right]^{2}}$

and the respective mass action law. For ideally dilute defects, this leads to a power law $\delta \propto p\left(\mathrm{O}_{2}\right)^{\mathrm{z}}$ with an exponent of $z=1 / 6$ in the regime of $\left[\mathrm{Pr}_{\mathrm{Ce}}^{\mathrm{X}}\right]>\left[\mathrm{Pr}_{\mathrm{Ce}}^{\prime}\right]$. Indeed the dashed lines in Fig. S1 exhibit slopes close to 1/6.

For the oxygen chemical potential in the interior of the catalyst particle it does not matter which reaction extracts $\mathrm{O}$ at the surface: $\mathrm{O}$ excorporation by low $p\left(\mathrm{O}_{2}\right)$ of an inert gas $/ \mathrm{O}_{2}$ mixture, or $\mathrm{O}$ excorporation by fast $\mathrm{CO}$ oxidation which removes $\mathrm{O}$ faster than the still present $p\left(\mathrm{O}_{2}\right)$ of the non-equilibrium gas mixture can re-supply it. Thus, it is a consistent procedure to determine the effective oxygen activity within the catalyst particles under $\mathrm{CO}$ oxidation conditions (i.e. in inert gas $/ \mathrm{O}_{2} / \mathrm{CO}$ mixture which is not in equilibrium) from the increased oxygen deficiency they acquire under these conditions (Figure 8). This is illustrated in Fig. S1. The black horizontal arrows represent the oxygen deficiencies of $2 \mathrm{PDC}$ in $1 \% \mathrm{O}_{2}+1 \% \mathrm{CO}$ mixture at different $T$ (Fig. 8c), and from the intersection with the extrapolated power laws for the respective temperatures the $p\left(\mathrm{O}_{2}\right)_{\text {eff }}$ values are obtained (Fig. 9a). The $p\left(\mathrm{O}_{2}\right)_{\text {eff }}$ found here are well within the stability range of ceria which extends at least down to $10^{-22}$ bar. ${ }^{11}$

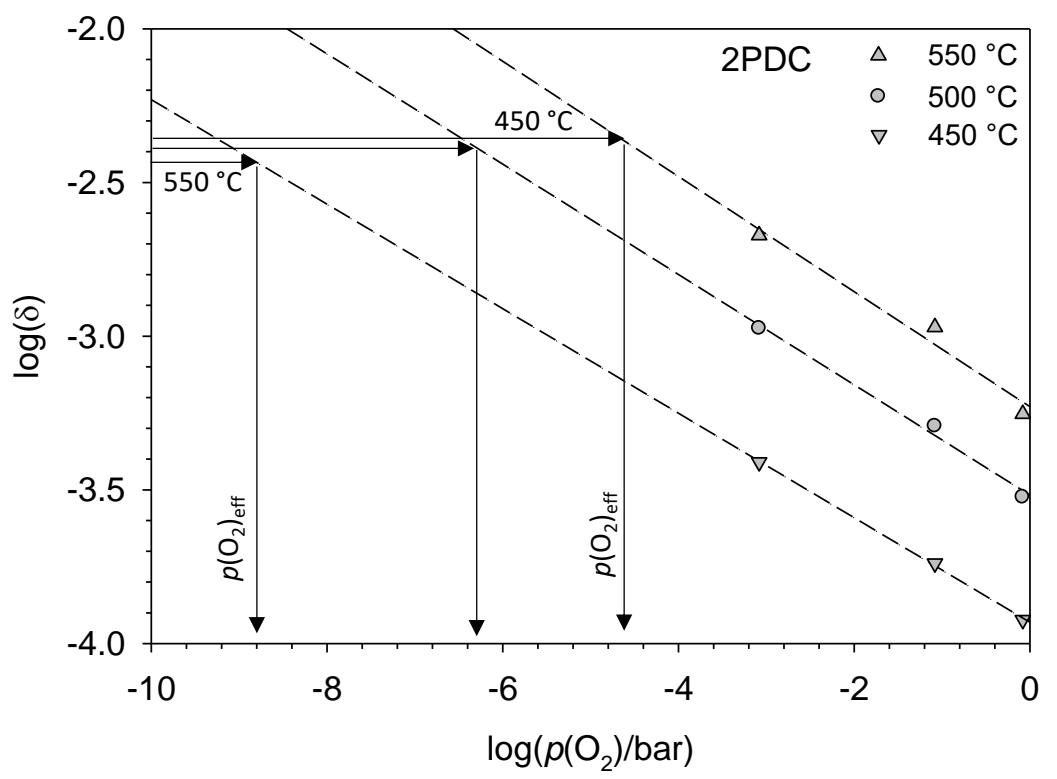

Figure S1: Example of extracting $p\left(\mathrm{O}_{2}\right)_{\text {eff }}$ values for $2 \mathrm{PDC}$ particles. The grey symbols are the measured oxygen deficiencies in inert gas $/ \mathrm{O}_{2}$ mixtures, which are extrapolated by the dashed lines accorgind to a power law. From the oxygen deficiencies under CO oxidation conditions (horizontal arrows, in $1 \% \mathrm{O}_{2}+1 \% \mathrm{CO}$ ) and the intersection with the dashed lines the $p\left(\mathrm{O}_{2}\right)_{\text {eff }}$ values are obtained. 


\section{XRD and Lattice Parameters}

XRD patterns and lattice parameters for doped ceria samples can be found in ref. ${ }^{10}$. For the Pr-doped zirconia samples and YSZ, the XRD patterns are given inFigure S2 (for doped ceria samples see ref. ${ }^{10}$ ) and all lattice parameters are listed in Table S2.

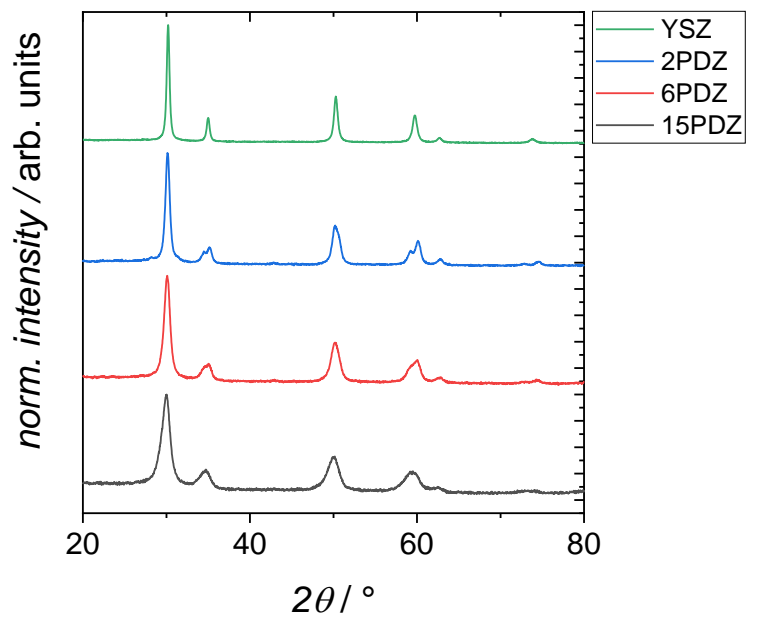

Figure S2: XRD patterns for 2, 6, and 15 mol\% Pr-doped ceria (PDZ) and 8 mol\% Ystabilized zirconia (YSZ).

Table S2: Lattice parameter of the doped samples.

\begin{tabular}{cccc}
\hline Sample & $\boldsymbol{a} / \AA$ & Sample & $\boldsymbol{a} / \AA$ \\
\hline 20PDC & 5.412 & 2NDC & 5.415 \\
6PDC & 5.412 & YSZ & 5.141 \\
2PDC & 5.410 & $15 \mathrm{PDZ}$ & 5.156 \\
0.6PDC & 5.412 & $6 \mathrm{PDZ}$ & $3.597,5.168^{*}$ \\
20GDC & 5.420 & $2 \mathrm{PDZ}$ & $3.598,5.187^{*}$ \\
2GDC & 5.408 & & \\
\hline
\end{tabular}

*Tetragonal unit cell which contains four formula units, pseudocubic lattice parameters are $5.121 \AA$ for $2 \mathrm{PDZ}$ and $5.114 \AA$ for $6 \mathrm{PDZ}$

\section{Raman spectra}

The peak at $465 \mathrm{~nm}$ is assigned to the $\mathrm{F}_{2 \mathrm{~g}}$ mode of regular lattice vibrations. The peak at $570 \mathrm{~nm}$ is assigned to the presence of oxygen vacancies. ${ }^{12,}{ }^{13}$ It increases systematically with the overall $\operatorname{Pr}$ concentration, indicating a corresponding increase of $\left[\mathrm{V}_{0}^{*}\right]$.
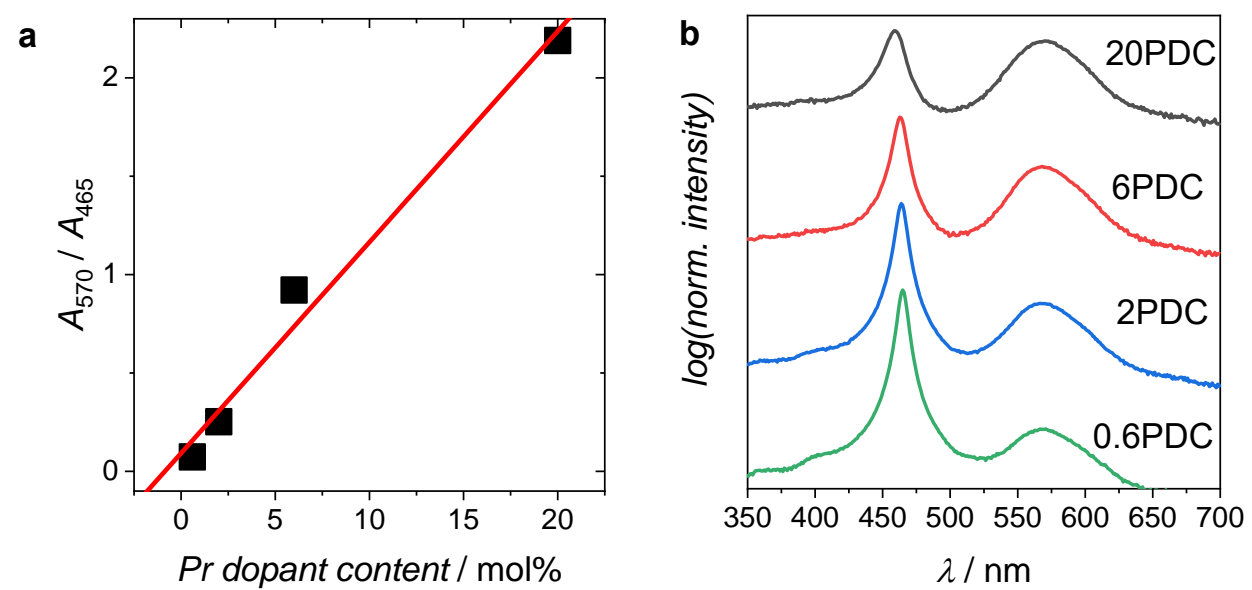

Figure S3: a) Raman peak intensity ratio as function of total Pr concentration, b) Raman spectra of PDC particles (spectra are shifted vertically for clarity). 


\section{SEM images}

No analysis of the dominating surface orientation was performed. However, the most stable terminating on ceria is (111), followed by (110) and (100) ${ }^{14}$. Since the sample powders are pre-treated prior measurement at $750{ }^{\circ} \mathrm{C}$, it is assumed that the surface is reconstructed to the thermodynamically favored (111) termination. The SEM images for doped ceria and zirconia samples are given in Figure S4. The flaky nature of the samples is caused by the combustion synthesis process.
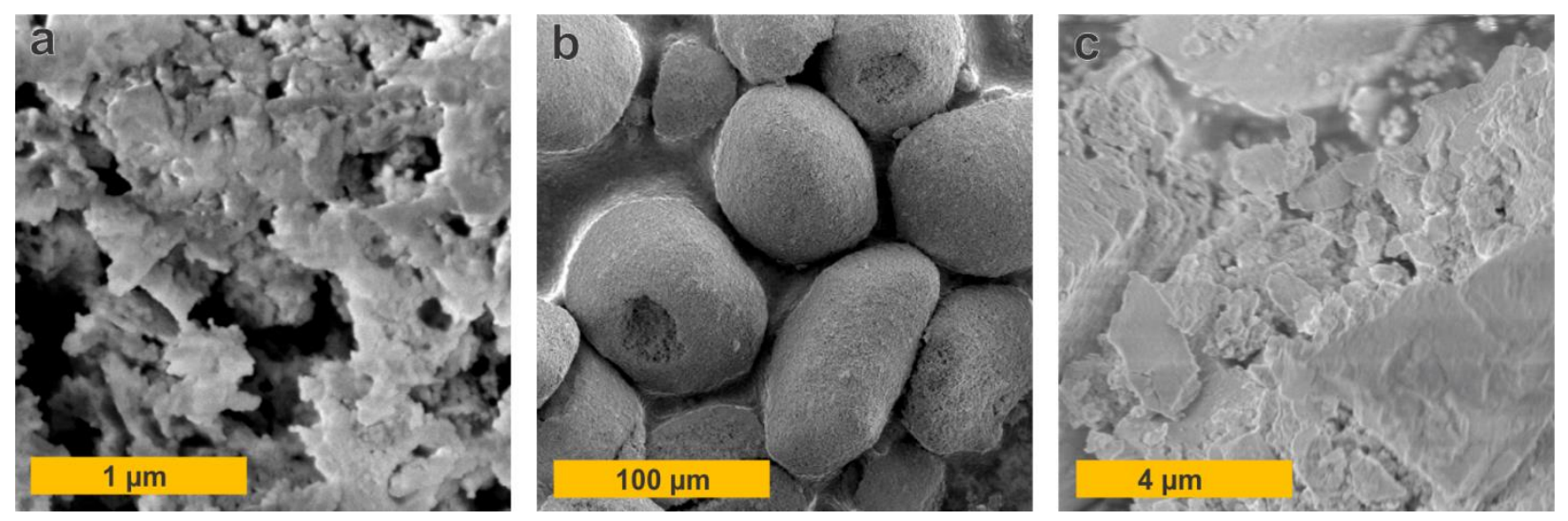

Figure S4: SEM images for doped ceria and zirconia calcined powder samples.

\section{BET Surface area}

The BET surface areas for the samples are listed in Table S3.

Table S3: Measured BET surface areas of the calcined sample powders used in this study.

\begin{tabular}{cccc}
\hline Sample & BET / $\mathbf{~ m}^{\mathbf{2}} \mathbf{g}^{-\mathbf{1}}$ & Sample & BET / $\mathbf{~ m}^{\mathbf{2}} \mathbf{g}^{\mathbf{- 1}}$ \\
\hline 20PDC & 20.8 & $2 \mathrm{NDC}$ & 17.6 \\
6PDC & 24.6 & YSZ & 13.5 \\
2PDC & 23.8 & $15 \mathrm{PDZ}$ & 35.8 \\
0.6PDC & 21.0 & $6 \mathrm{PDZ}$ & 10.3 \\
20GDC & 20.6 & $2 \mathrm{PDZ}$ & 4.4 \\
2GDC & 17.5 & & \\
\hline
\end{tabular}

\section{Mass balance}

The mass balance of carbon, hydrogen and oxygen was always checked. The deviation from the mass balance for carbon and oxygen is in the range of $\pm 2-5 \%$ for both, $\mathrm{CO}$ and $\mathrm{CH}_{4}$ oxidation (Fig. S5a for $\mathrm{CO}$ and $\mathrm{S} 5 \mathrm{~b}$ for $\mathrm{CH}_{4}$ ). In case of hydrogen, the deviation is up to $\pm 10 \%$. The probed catalysts reached a steady state after a few minutes. 

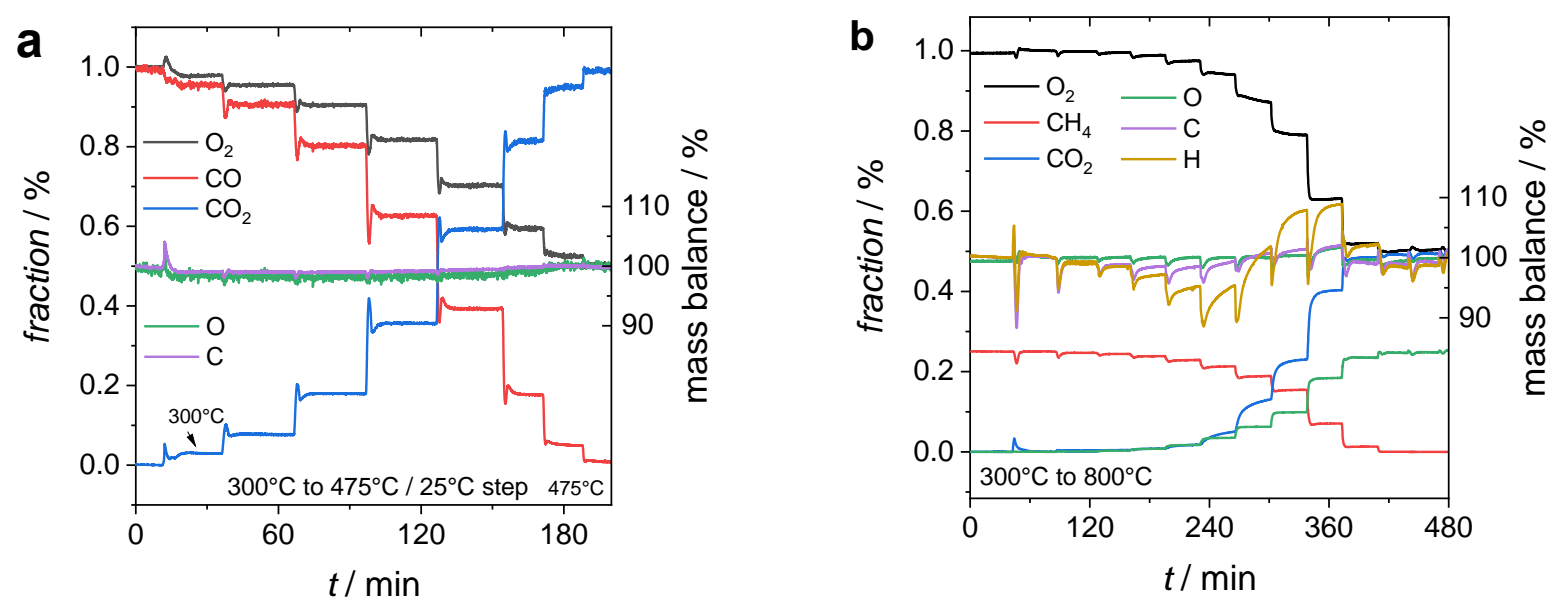

Figure S5: Measured reactant and product gas phase fractions for a) CO oxidation and b) $\mathrm{CH}_{4}$ oxidation for $20 \mathrm{GDC}$ in $1 \% \mathrm{O}_{2}$ with $1 \% \mathrm{CO}$ with a flow rate of $10 \mathrm{~mL} \mathrm{~min}-1$. The right scale displays the mass balance (green, violet and yellow lines), which have only little deviation from $100 \%$.

\section{Methane Oxidation}

Figure $\mathrm{S} 6$ shows the dopant dependence of the reaction rate of $\mathrm{CH}_{4}$ oxidation $R_{\mathrm{CH}_{4}}$. Only a weak dependence according to $R_{\mathrm{CH}_{4}} \propto[\mathrm{Pr}]^{0.3}$ or $R_{\mathrm{CH}_{4}} \propto[\mathrm{Gd}]^{0.2}$ was observed. Fig. S7 shows the $p\left(\mathrm{O}_{2}\right)$ and $p\left(\mathrm{CH}_{4}\right)$ dependence of $R_{\mathrm{CH}_{4}}$. Only a weak $p\left(\mathrm{O}_{2}\right)$ dependence was found, but the reaction order in $p\left(\mathrm{CH}_{4}\right)$ is between 0.8 and 0.9 .
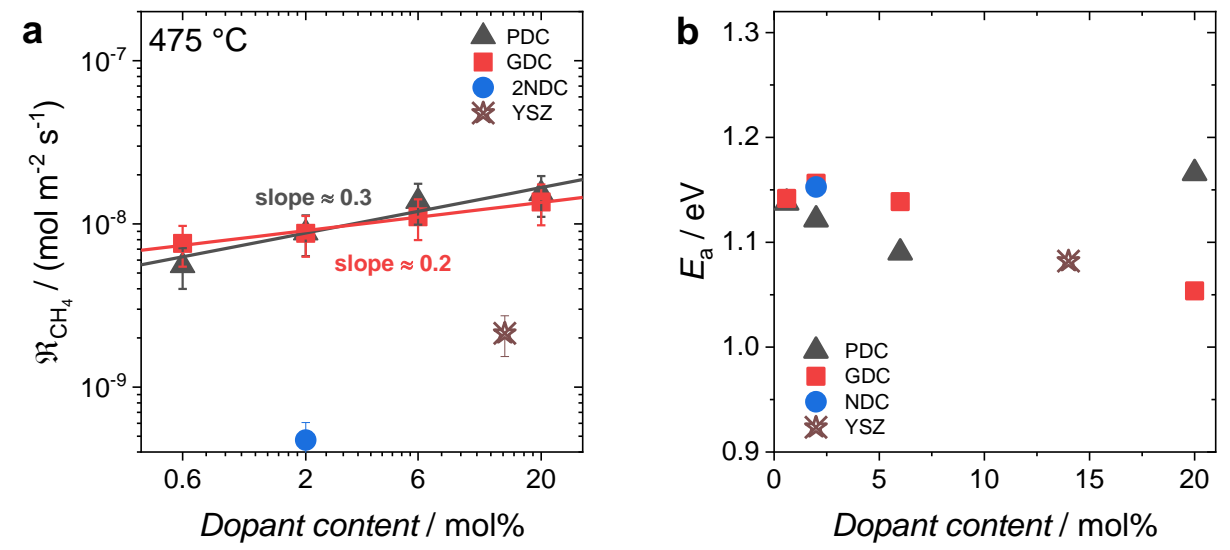

Figure S6: a) Calculated $\mathrm{CH}_{4}$ oxidation reaction rates as a function of dopant concentration. b) Apparent activation energy of the $\mathrm{CH}_{4}$ oxidation as a function of dopant concentration.
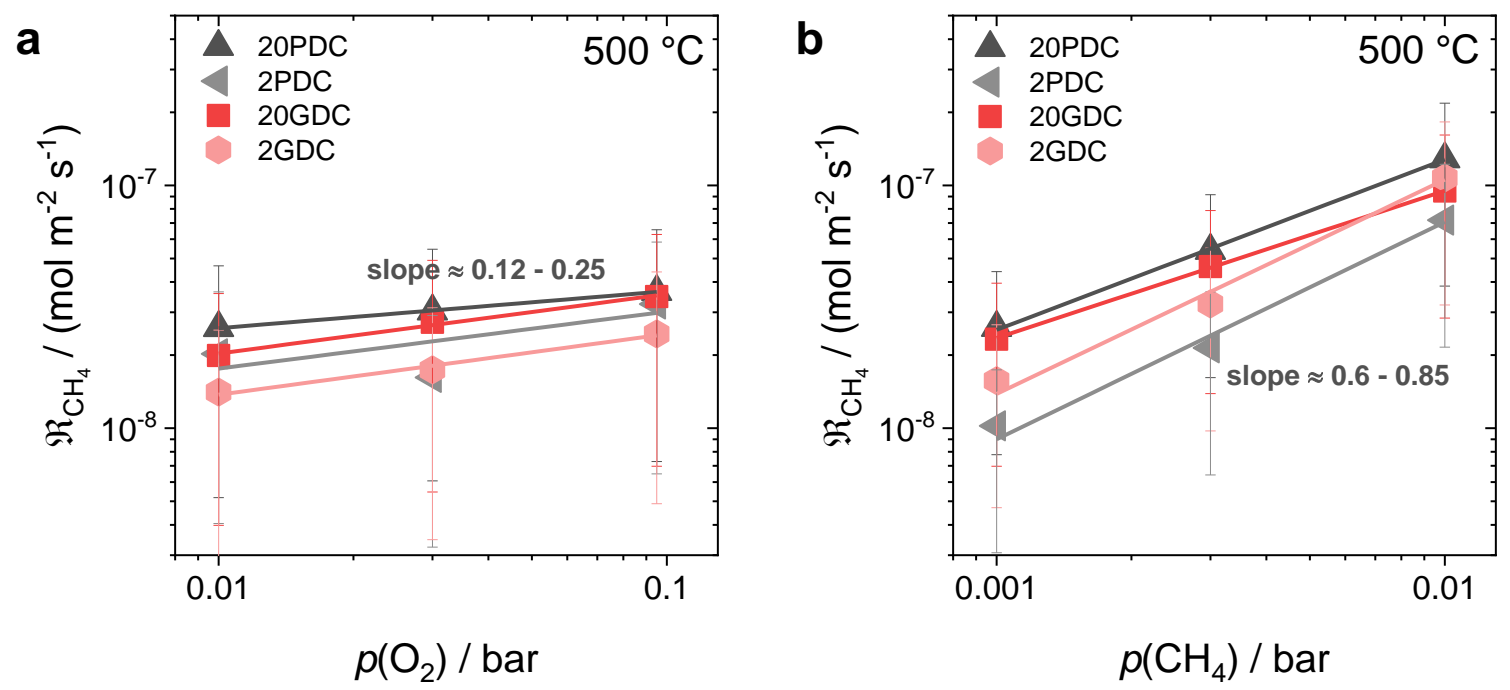

Figure S7: a) $\mathrm{CH}_{4}$ oxidation reaction rate as a function of $\mathrm{O}_{2}$ partial pressure and b) $\mathrm{CH}_{4}$ partial pressure for doped ceria. 


\section{Impedance Spectroscopy}

Fig. S8 displays the measured impedance data for 2 and $20 \mathrm{GDC}$ at $450{ }^{\circ} \mathrm{C}$ in oxygen and with additional $\mathrm{CO}$. The high frequency arc is attributed to bulk response due to the typical low capacitance of around $10^{-12} \mathrm{~F}$. Prominent blocking grain boundaries are not observed under these conditions because (i) the higher the dopant content the smaller the blocking effect, thus for 20GDC the GB blocking is weak anyway. (ii) for 2GDC a blocking GB arc is observed at lower $T$, but its magnitude relative to the bulk arc decreases with increasing $T$ because of its higher activation energy.
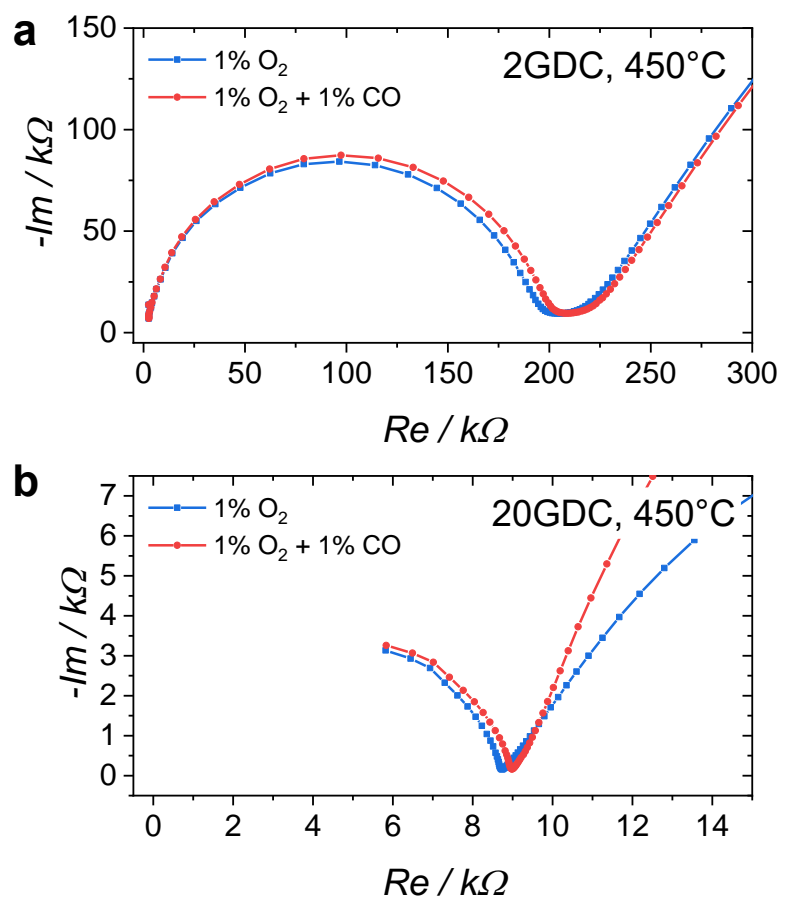

Figure S8: Nyquist plot for a) 2GDC and b) 20GDC in $1 \% \mathrm{O}_{2}$ and in $1 \% \mathrm{O}_{2}$ plus $1 \% \mathrm{CO}$.

\section{PDC and GDC particles: bulk diffusion versusus surface limitation}

For a sample with diameter $l$, the critical length $l_{\mathrm{c}}=D^{*} / k^{*}$ determines whether surface-limited conditions $\left(l<l_{c}\right.$, no concentration gradients within the particles) or diffusion limitation ( $l>l_{c}$, pronounced concentration gradients within the particles) prevails ${ }^{15}$. For oxygen isotope exchange, $l_{\mathrm{c}}$ calculated from $k^{*}$ values from ref. 10 and $D^{*}$ from refs. ${ }^{16}, 17$ is in the range of $1400 \mu \mathrm{m}$ and $500 \mu \mathrm{m}$ for 20GDC and 20PDC at $500{ }^{\circ} \mathrm{C}$. With decreasing temperature, $l_{\mathrm{c}}$ increases because $k^{*}$ has a higher activation energy compared to $D^{*}$.

For the equilibration of oxygen chemical potential during $\mathrm{CO}$ oxidation, the chemical $k^{\delta}, D^{\delta}$ are the relevant quantities, which, however, differ from $D^{*}, k^{*}$ only by the thermodynamic factor $\omega_{0} . \omega_{0}$ is given by the bulk defect chemistry, thus identical for $k$ and $D$, and cancels for $l_{\text {c }}$. For 20PDC, the CO oxidation rate $\mathfrak{R}_{\mathrm{CO}}$ and the oxygen exchange rate $\Re_{0}$ are comparable (no significantly decreased $p\left(\mathrm{O}_{2}\right)_{\text {eff }}$ in Fig. 8 of the main paper), thus the critical length is similar to the isotope exchange case, and the catalyst particles $<60 \mu \mathrm{m}$ diameter of Fig. 8 are clearly in surface-controlled conditions. For lower Pr concentration, $\Re_{\mathrm{CO}}$ remains unchanged (Fig. 6a) while $D^{*}$ is expected to moderately decrease $\left(D^{*}\right.$ is proportional to $\left.\left[\mathrm{V}_{0}^{*}\right]\right)$. For $2 \mathrm{PDC}$ the estimated $l_{\mathrm{c}}$ is still comparable to the particle diameter, i.e. the sample is still largely in the surface-controlled regime. Owing to their particle size below $1 \mu \mathrm{m}<<$ $l_{c}$, as-calcined powders and the porous pellets used for conductivity measurements 
under CO oxidation conditions are always fully in surface-limited conditions. The GDC particles (60 $\mu \mathrm{m}$ diameter) have the same $\mathrm{CO}$ oxidation rate as the $\mathrm{PDC}$ samples (Fig. 6a) but decreased $D^{*}$ values (ref. ${ }^{16}$ ), thus at $500{ }^{\circ} \mathrm{C}$ they move towards mixed surface and diffusion control. At lower $T$, again surface control prevails. The observation that GDC shows no significant weight difference between $1 \% \mathrm{O}_{2}$ and 1 $\% \mathrm{O}_{2}+1 \% \mathrm{CO}$ is not caused by a change to diffusion control (even under diffusion control the outer region of the particle experiences the decreased $\left.p\left(\mathrm{O}_{2}\right)_{\mathrm{eff}}\right)$, but rather by the fact that in absence of easily reducible cations the oxygen stoichiometry of GDC is insensitive to $p\left(\mathrm{O}_{2}\right)$ changes as shown in Fig. 2 a.

\section{References}

1. Bishop, S. R.; Stefanik, T. S.; Tuller, H. L., Electrical conductivity and defect equilibria of $\mathrm{Pr}_{0.1} \mathrm{Ce}_{0.9} \mathrm{O}_{2-\delta}$. Physical Chemistry Chemical Physics 2011, 13, 10165-10173.

2. Tai, L. W.; Lessing, P. A., Modified resin intermediate processing of perovskite powders 2: processing for fine nonagglomerated Sr-doped lanthanum chromite powders. Journal of Materials Research 1992, 7, 511-519.

3. Tai, L. W.; Lessing, P. A., Modified resin intermediate processing of perovskite powders 1: Optimization of polymeric precursors. Journal of Materials Research 1992, 7, 502-510.

4. Balaguer, M.; Yoo, C.-Y.; Bouwmeester, H. J. M.; Serra, J. M., Bulk transport and oxygen surface exchange of the mixed ionic-electronic conductor $\mathrm{Ce}_{1-\mathrm{x}} \mathrm{Tb}_{\mathrm{x}} \mathrm{O}_{2-\delta}(\mathrm{x}=0.1,0.2,0.5)$. Journal of Materials Chemistry A 2013, 1, 10234-10242.

5. Yoo, C.-Y.; Bouwmeester, H. J. M., Oxygen surface exchange kinetics of $\mathrm{SrTi}_{1-x} \mathrm{Fe}_{\mathrm{x}} \mathrm{O}_{3-\delta}$ mixed conducting oxides. Physical Chemistry Chemical Physics 2012, 14, 11759-11765.

6. Yoo, C.-Y.; Boukamp, B. A.; Bouwmeester, H. J. M., Oxygen surface exchange kinetics of erbiastabilized bismuth oxide. Journal of Solid State Electrochemistry 2011, 15, 231-236.

7. Bouwmeester, H. J. M.; Song, C.; Zhu, J.; Yi, J.; Annaland, M. v. S.; Boukamp, B. A., A novel pulse isotopic exchange technique for rapid determination of the oxygen surface exchange rate of oxide ion conductors. Physical Chemistry Chemical Physics 2009, 11, 9640-9643.

8. Yoo, C.-Y.; Boukamp, B. A.; Bouwmeester, H. J. M., Oxygen surface exchange kinetics on $\mathrm{PrBaCO}_{2} \mathrm{O}_{5+\delta}$. Solid State lonics 2014, 262, 668-671.

9. Saher, S.; Naqash, S.; Boukamp, B. A.; Hu, B.; Xia, C.; Bouwmeester, H. J. M., Influence of ionic conductivity of the nano-particulate coating phase on oxygen surface exchange of $\mathrm{La}_{0.58} \mathrm{Sr}_{0.4} \mathrm{Co}_{0.2} \mathrm{Fe}_{0.8} \mathrm{O}_{3-\delta}$. Journal of Materials Chemistry A 2017, 5, 4991-4999.

10. Schaube, M.; Merkle, R.; Maier, J., Oxygen exchange kinetics on systematically doped ceria: a pulsed isotope exchange study. Journal of Materials Chemistry A 2019, 7, 21854-21866.

11. Tuller, H. L.; Nowick, A. S., Defect structure and electrical properties of nonstoichiometric $\mathrm{CeO}_{2}$ single crystals. J. Electrochem. Soc. 1979, 126, 209-217.

12. Li, L.; Chen, F.; Lu, J.-Q.; Luo, M.-F., Study of defect sites in $\mathrm{Ce}_{1-x} \mathrm{M}_{\mathrm{x}} \mathrm{O}_{2-\delta}(\mathrm{x}=0.2)$ solid solutions using Raman spectroscopy. J. Phys. Chem. A 2011, 115, 7972-7977.

13. Ahn, K.; Yoo, D. S.; Prasad, D. H.; Lee, H.-W.; Chung, Y.-C.; Lee, J.-H., Role of multivalent Pr in the formation and migration of oxygen vacancy in Pr-doped ceria: Experimental and first-principles investigations. Chem. Mater. 2012, 24, 4261-4267.

14. Nolan, M.; Grigoleit, S.; Sayle, D. C.; Parker, S. C.; Watson, G. W., Density functional theory studies of the structure and electronic structure of pure and defective low index surfaces of ceria. Surface Science 2005, 576, 217-229.

15. Bouwmeester, H. J. M.; Kruidhof, H.; Burggraaf, A. J., Importance of the surface exchange kinetics as rate limiting step in oxygen permeation through mixed-conducting oxides. Solid State lonics 1994, 72, 185-194.

16. Manning, P. S.; Sirman, J. D.; Kilner, J. A., Oxygen self-diffusion and surface exchange studies of oxide electrolytes having the fluorite structure. Solid State lonics 1996, 93, 125-132.

17. Fagg, D. P. ; Shaula, A. L.; Kharton, V. V.; Frade, J. R., High oxygen permeability in fluorite-type $\mathrm{Ce}_{0.8} \mathrm{Pr}_{0.2} \mathrm{O}_{2-\delta}$ via the use of sintering aids. J. Membr. Sci. 2007, 299, 1-7. 